\title{
Preventing the Spread of COVID-19 to Community Hospitals in Singapore
}

\author{
Lifeng Tan $^{1}$, Fe Marie Curameng ${ }^{2}$, and Linus Chua ${ }^{2}$ \\ ${ }^{1}$ Alexandra Health Pte Ltd \\ ${ }^{2}$ National University Health System
}

June 3, 2020

\begin{abstract}
COVID-19 is a global pandemic with extensive community spread in many countries. Community hospitals (CHs) have an important role to play in offloading patients from acute hospitals and providing a longer period of rehabilitation and convalescence. Patients in $\mathrm{CHs}$ tend to have more chronic medical issues and are older in age and are hence particularly vulnerable should COVID-19 spread in such facilities. As such measures have to be put in place to protect this group and we share the practices put in place by CHs in Singapore in response to COVID-19.
\end{abstract}

\section{Hosted file}

COVID CH IJCP.docx available at https://authorea.com/users/329381/articles/456530-preventingthe-spread-of-covid-19-to-community-hospitals-in-singapore 